\title{
Mixoploidy combined with aneuploidy in a 13 year-old patient with severe multiple congenital abnormalities and intellectual disability
}

\author{
Laura J. C. M. van Zutven ${ }^{1}$ (iD $\mid$ Grazia M. S. Mancini ${ }^{1}$ (iD | \\ Karen G. C. B. Bindels-de Heus ${ }^{2}$ | Erica L. T. van den Akker ${ }^{2}$ । \\ Lorette O. M. Hulsman ${ }^{1}$ | Marjan Smit ${ }^{1}$ | H. Berna Beverloo ${ }^{1}$ \\ ${ }_{1}^{1}$ Department of Clinical Genetics, Sophia Children's Hospital, Erasmus MC, Rotterdam, The Netherlands \\ ${ }^{2}$ Department of Pediatrics, Sophia Children's Hospital, Erasmus MC, Rotterdam, The Netherlands \\ Correspondence \\ Dr. Laura J.C.M. van Zutven, Department of Clinical Genetics, Sophia Children's Hospital, Erasmus Medical Center, P.O. Box 2040, 3000 CA Rotterdam, \\ The Netherlands. \\ Email: I.vanzutven@erasmusmc.nl
}

To the Editor:

We report on a 13-year-old female patient, born from healthy, non-consanguineous parents. She was born at 37 weeks gestation by cesarean section because of meconium stained amniotic fluid and late fetal heart decelerations. After birth she required assisted ventilation because of respiratory insufficiency. During intubation a posterior mucosal cleft palate and bifid uvula were noted. She was small for gestational age (weight 1,780 gram, $-3 \mathrm{SD}$; head circumference at -1.2 SD) and showed dysmorphic features with frontal bossing, rethrognatia, hyperplastic gums, large fontanelles, single transverse palmar creases, ulnar deviation of wrists, bilateral clubfeet and syndactyly of toes 1-5th. No cardiac or other visceral abnormalities were detected. In time, developmental milestones were delayed. Her growth rate was also delayed and at the age of 6 years (Figure 1a) height followed the $-4 \mathrm{SD}$, with an average head circumference for the age. Examination at age 6 years showed metopic synostosis, high-arched eyebrows, flattened orbital ridges, small chin, prominent front teeth, short philtrum, congenital contractures of fingers, elbows and knees (Figure 1b), broad thorax with widely separated nipples (Figure 1c), thoracic scoliosis, high-pitched voice, nasal speech and hypotonia. Failure to thrive required gastric tube feedings. She also presented with mild-moderate intellectual disability. Brain MRI at 4 years showed a retrocerebellar arachnoidal cyst and thin corpus callosum. Metabolic screening shortly after birth was normal. Because she displayed mild features resembling Bohring-Opitz trigonocephaly, the ASXL1 gene was analyzed by capillary sequencing of the coding regions in DNA extracted from blood. No pathogenic variants in this gene were detected. G-banded chromosome analysis shortly after birth revealed a 45,X complement in peripheral blood, consistent with Turner syndrome. As the girl's phenotype could not be explained by this Turner karyotype, additional genetic analyses were performed.

Subtelomeric MLPA (SALSA P036C en P070 kits, MRC Holland) and genomic array (Affymetrix $250 \mathrm{k} \mathrm{Nsp} 1$ array) analysis using DNA obtained from peripheral blood confirmed the 45,X karyotype. Additionally, array showed a small variant of unknown significance, inherited from the healthy father (114 kb interstitial loss on chromosome $4 \mathrm{q} 31.22$, containing part of the glycophorin $\mathrm{E}$ and $\mathrm{B}$ genes).

As still no satisfactory explanation for the girl's phenotype was found, a mosaic genetic aberration was suspected. Therefore, genomic array was repeated on the Illumina HumanCyto12-SNP array using DNA obtained from a skin biopsy. An abnormal profile was observed, suggesting the presence of a triploid cell line with loss of one $X$ chromosome. Based on the B-allele frequency, this cell line could possibly be present in a high mosaic form, that is, in more than $75 \%$ of the cells (Figure 2a). Subsequent karyotyping on cultured skin fibroblasts indeed showed a mosaic karyotype: 68,XX[5]/45,X[1] (Figure 2b), confirming the array findings.

In conclusion, the patient's phenotype can be explained by a tissue specific mosaic abnormal karyotype with both an abnormal triploid and an abnormal diploid cell line being present (mixoploidy). Mixoploidy has been described in only a few patients worldwide, generally displaying severe congenital abnormalities, such as growth restriction, hypotonia, intellectual disability, body asymmetry, syndactyly, obesity, 

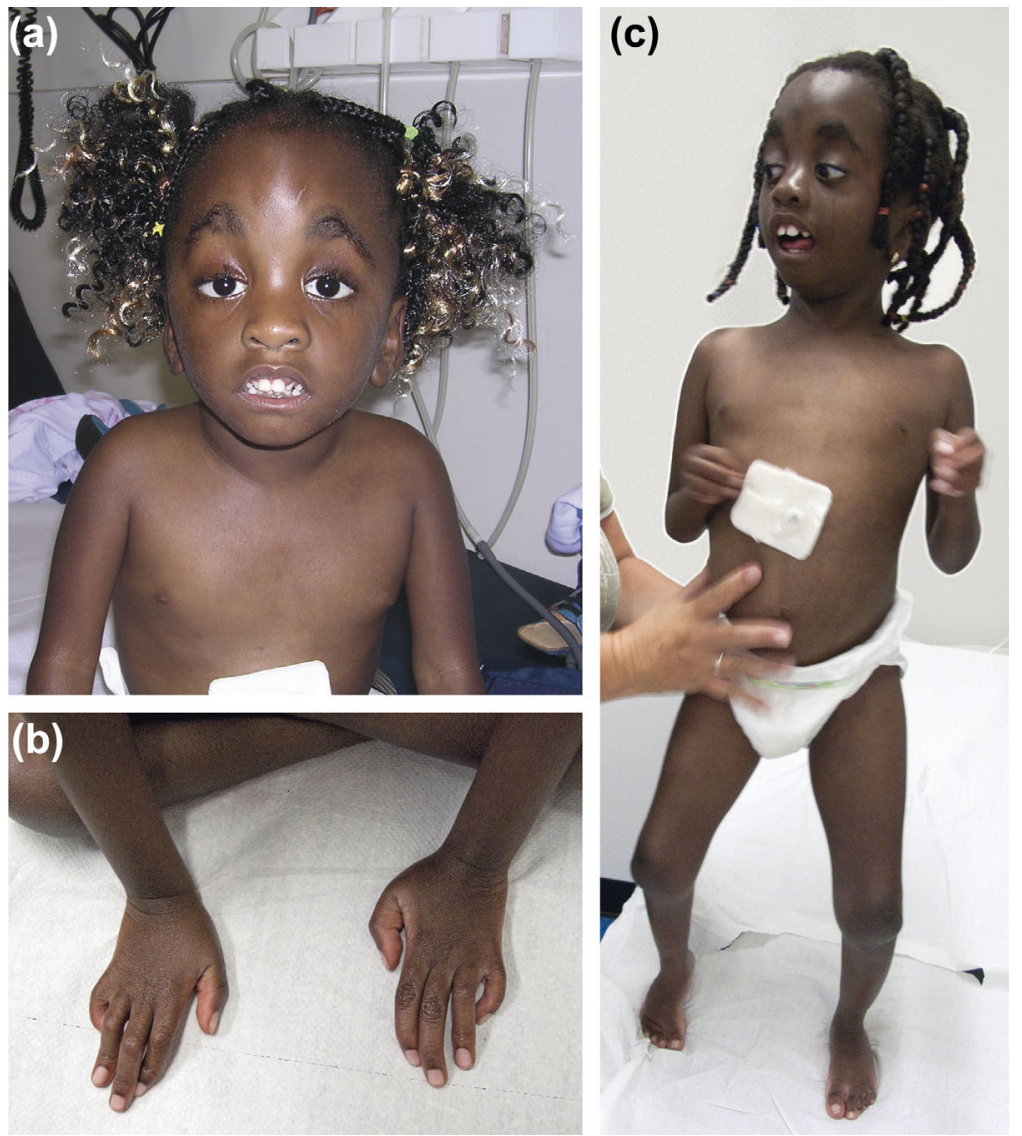

FIGURE 1 Photographs of the patient (age 6), showing high-arched eyebrows, flattened orbital ridges, metopic ridge, bilateral ptosis, lowset ears, small chin, prominent front teeth, short philtrum (a), contractures of the fingers, with peculiar 5th finger clinodactyly (b), and knees and broad thorax with widely spaced nipples and disproportioned short stature (c). [Color figure can be viewed at wileyonlinelibrary.com]

and sometimes aberrant skin pigmentation (Boonen, Hoffmann, Donnai, Tümer, \& Ravn, 2011, van de Laar et al., 2002). In these patients, peripheral blood usually showed a normal karyotype, whereas the triploid cell line was present only in other tissues, as was observed in the presented patient. Retrospectively, the dysmorphic features and congenital abnormalities in our patient resemble earlier descriptions of triploid/diploid mixoploidy syndrome (Boonen et al., 2011, van de Laar et al., 2002). However, in combination with features of a Turner phenotype, these were difficult to recognize.

The combination of mixoploidy with an aneuploidy, as observed in our patient, is extremely rare. In the few patients reported to date, the aneuploidy was mostly observed only in the diploid cell line, but not in the triploid cell line, for example, 45,X/69,XXY (Betts, Fear, Barby, \& Seller, 1989; Quigley et al., 2005) or 47,XX,+15/69,XXX (Dean et al., 1997). One other patient we are aware of with an aneuploidy both in the diploid and the triploid cell line was a fetus with $70, X X X,+18$ in chorionic villus sampling and $47, X X,+18$ in fetal fibroblasts (Tuerlings, Breed, Vosters, \& Anders, 1993). In this case however, the triploidy may have been confined to the placenta rather than a true mixoploidy being present in the fetus. Recently, the karyotypic combination observed in our patient has been reported for the first time in a 3-month-old girl with failure to thrive, dysmorphic craniofacial features, hypotonia, and left ventricular non-compaction (Posey et al., 2016). Our patient, with information available at different ages, demonstrates an even more pronounced clinical phenotype, possibly related to the different level of mosaicism in tissues and organs.

Our observation underscores the importance of re-examination and second tissue analysis of patients with multiple congenital anomalies when genome (in this case microarray copy number) analysis appears normal.

\section{ACKNOWLEDGMENT}

We thank Tom de Vriesch Lentsch for preparation of Figures 1 and 2.

\section{CONFLICTS OF INTEREST}

The authors declare that they have no conflict of interest.

\section{ORCID}

Laura J. C. M. van Zutven (iD http://orcid.org/0000-0002-1092-2610

Grazia M. S. Mancini (iD http://orcid.org/0000-0002-1211-9979 
(a)
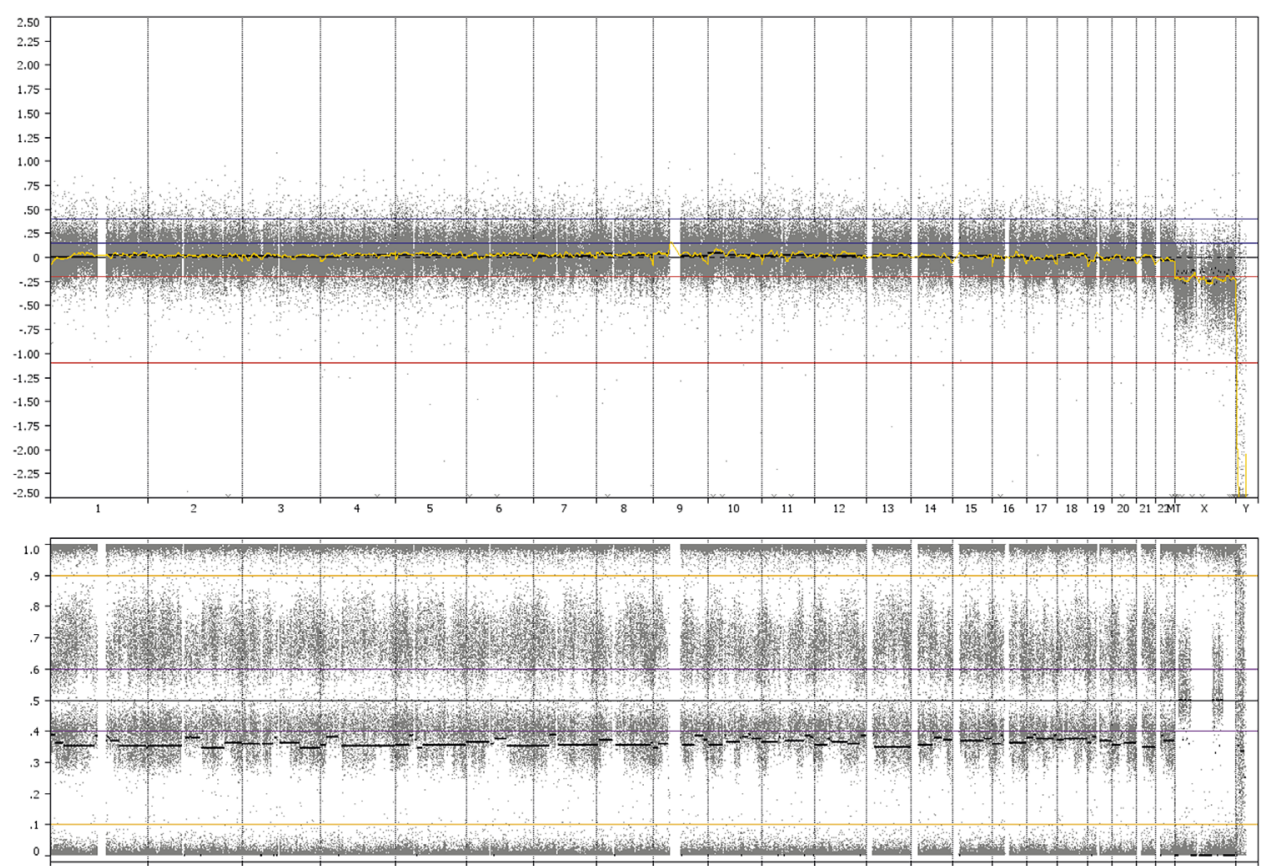

(b)
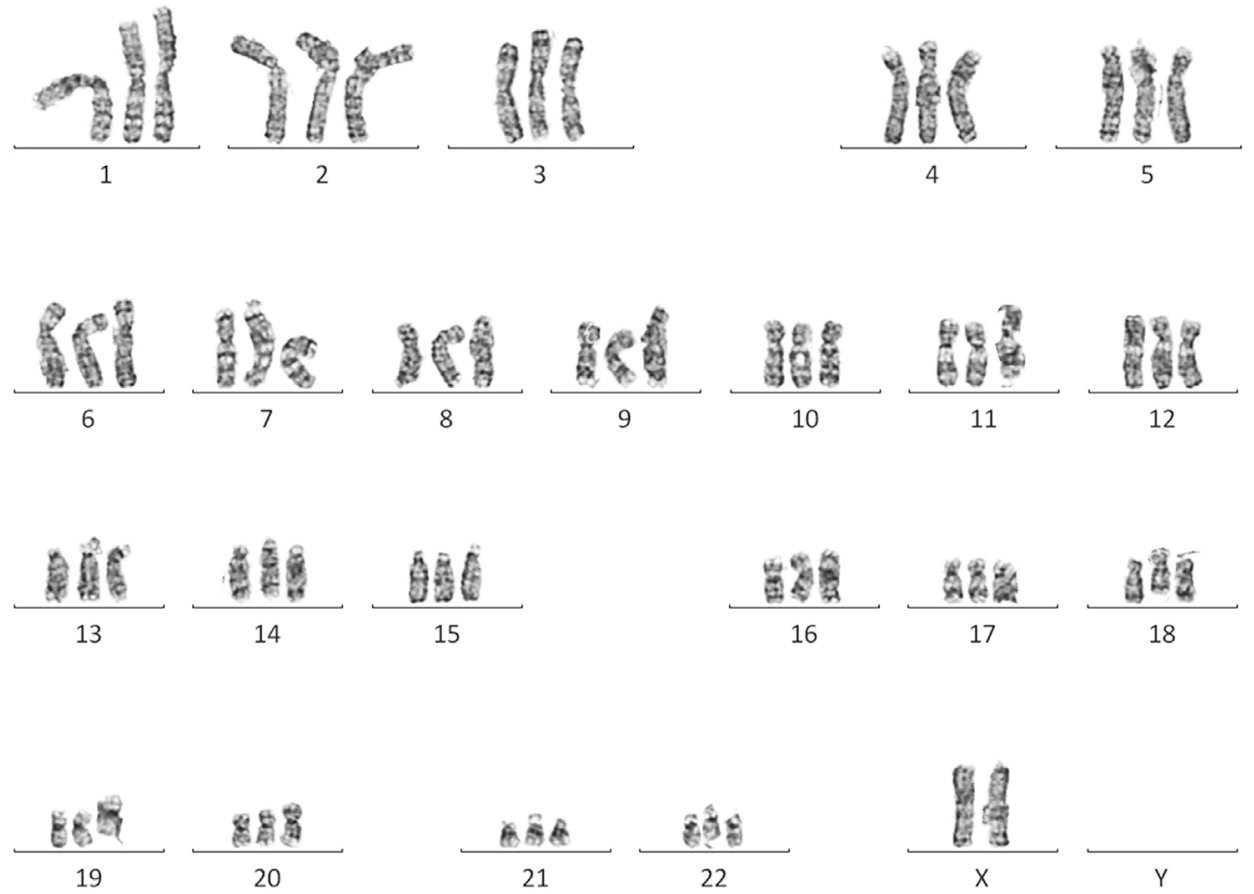

FIGURE 2 Array (a) and karyotyping (b) results obtained from skin biopsy, displaying a (high mosaic) triploidy. [Color figure can be viewed at wileyonlinelibrary.com]

\section{REFERENCES}

Betts, D. R., Fear, C. N., Barby, T., \& Seller, M. J. (1989). A 45,X/69,XXY fetus. Clinical Genetics, 35, 285-288.

Boonen, S. E., Hoffmann, A. L., Donnai, D., Tümer, Z., \& Ravn, K. (2011). Diploid/triploid mosaicism: A rare event or an underdiagnosed syndrome? European Journal of Medical Genetics, 54, 374-375. https://doi.org/10.1016/j.ejmg.2011.01.002
Dean, J., Cohen, G., Kemp, J., Robson, L., Tembe, V., Hasselaar, J., . . Smith, A. (1997). Karyotype $69, X X X / 47, X X,+15$ in a $21 / 2$ year old child. Journal of Medical Genetics Part A, 34, 246-249.

Posey, J. E., Mohrbacher, N., Smith, J. L., Patel, A., Potocki, L., \& Breman, A. M. (2016). Triploidy mosaicism $(45, X / 68, X X)$ in an infant presenting with failure to thrive. American Journal of Medical Genetics Part A, 170A, 694-698. 
Quigley, D. I., McDonald, M. T., Krishnamuthy, V., Kishnani, P. S., Lee, M. M., Haqq, A. M., Goodman, B. K. (2005). Triploid mosaicism in a 45,X/69, XXY infant. American Journal of Medical Genetics, 138A, 171-174.

Tuerlings, J. H., Breed, A. S., Vosters, R., \& Anders, G. J. (1993). Evidence of a second gamete fusion after the first cleavage of the zygote in a $47, \mathrm{XX}+$ 18/70,XXX + 18 mosaic. A remarkably diploid-triploid discrepancy after CVS. Prenatal Diagnosis, 13, 301-306.

van de Laar, I., Rabelink, G., Hochstenbach, R., Tuerlings, J., Hoogeboom, J., \& Giltay, J. (2002). Diploid/triploid mosaicism in dysmorphic patients. Clinical Genetics, 62, 376-382.
How to cite this article: van Zutven LJCM, Mancini GMS, Bindels-de Heus KGCB, et al. Mixoploidy combined with aneuploidy in a 13 year-old patient with severe multiple congenital abnormalities and intellectual disability. Am J Med Genet Part A. 2018;176A:492-495.

https://doi.org/10.1002/ajmg.a.38553 